\title{
Clinical evaluation of total intravenous anaesthesia using xylazine or dexmedetomidine with propofol in surgical management of canine patients
}

\author{
Biswadeep Jena ${ }^{1}$, Jayakrushna Das ${ }^{1}$, Indramani Nath ${ }^{1}$, Kautuk Kumar Sardar², Abhishek Sahoo ${ }^{3}$, \\ Sasanka Sekhar Beura ${ }^{4}$ and Abhishek Painuli ${ }^{5}$
}

1. Department of Veterinary Surgery \& Radiology, College of Veterinary Science \& Animal Husbandry, Orissa University of Agriculture and Technology, Bhubaneswar, Odisha, India; 2. Department of Veterinary Pharmacology \& Toxicology, College of Veterinary Science \& Animal Husbandry, Orissa University of Agriculture and Technology, Bhubaneswar, Odisha, India; 3. Department of Animal Nutrition, College of Veterinary Science \& Animal Husbandry, Orissa University of Agriculture and Technology, Bhubaneswar, Odisha, India; 4. Department of Livestock Production \& Management, College of Veterinary Science \& Animal Husbandry, Orissa University of Agriculture and Technology, Bhubaneswar, Odisha, India; 5. Department of Veterinary Surgery \& Radiology, G. B. Pant University of Agriculture \& Technology, Pantnagar (Usham Singh Nagar), Uttarakhand, India.

Corresponding author: Biswadeep Jena, email: biswadeep44@gmail.com, JD: drjohndasjajpur@yahoo.co.in,

IN: indravet@yahoo.co.in, KKS: kksardar@gmail.com, AS: draviseq@gmail.com, SSB: sasankavet41@gmail.com, AP: painuliabhishek177@gmail.com

Received: 08-05-2014, Revised: 22-07-2014, Accepted: 27-07-2014, Published online: 13-09-2014

doi: 10.14202/vetworld.2014.671-680. How to cite this article: Jena B, Das J, Nath I, Sardar KK, Sahoo A, Beura SS, Painuli A (2014) Clinical evaluation of TIVA using xylazine or dexmedetomidine with propofol in surgical management of canine patients, Veterinary World 7(9): 671-680.

\begin{abstract}
Aim: The aim was to evaluate and compare the clinico-physiological, hemodynamic and hematobiochemical effects in response to different total intravenous anaesthesia techniques using xylazine or dexmedetomidine with propofol in canine patients.

Materials and Methods: Under a prospective randomized blinded clinical study, 12 apparently healthy adult dogs $(14.27 \pm 3.2 \mathrm{~kg})$ divided into two groups $(\mathrm{n}=6)$. Animals were administered with xylazine $(0.5 \mathrm{mg} / \mathrm{kg}$ body weight IV) in X group or, dexmedetomidine (10 $\mu \mathrm{g} / \mathrm{kg}$ body weight IV) in D group and propofol (as IV bolus till the induction and continuous IV infusion for maintenance). Clinical reflexes, physiological, hemodynamic parameters, were recorded at 5-min intervals. Blood was collected at zero, 30 and 60 min after initial injection for hematobiochemical evaluation. Statistical analysis was performed using analysis of variance, Duncan's multiple range tests, paired - t-test and Kruskal-Wallis one-way test.

Results: Animals showed quicker attenuation of all clinical reflexes in group D. Induction doses of propofol were $3.17 \pm 0.21$ and $2.72 \pm 0.15 \mathrm{mg} / \mathrm{kg}$ and rate of infusion of propofol for maintenance of anaesthesia were $0.33 \pm 0.02 \mathrm{mg} / \mathrm{kg} / \mathrm{min} \mathrm{and}$ $0.35 \pm 0.02 \mathrm{mg} / \mathrm{kg} / \mathrm{min}$ respectively in group X and D. Recovery was quicker in group D. There were no significant statistical differences in physiological, hemodynamic and hematobiochemical parameters in both the groups. There were no adverse effects after recovery.

Conclusion: Both anesthetic protocols provided satisfactory immobilization, but dexmedetomidine-propofol combination may be preferred owing to slightly better degree of basal anaesthesia, lesser doses of propofol required for induction and maintenance of anaesthesia along with a lesser degree of respiratory depression. However, there was no clear preference for either of the protocol, and both appear suitable for canines.
\end{abstract}

Keywords: alpha2 adrenoreceptor agonist, canine surgery, dexmedetomidine, propofol, total intravenous anaesthesia, xylazine.

\section{I ntroduction}

Surgical management of canine patients, being a painful and inflammatory response, always necessitate an ideal anesthetic, which produces sleep, amnesia, analgesia and muscle relaxation to facilitate well-being of the surgical patient [1]. Inability of a sole agent to achieve aforementioned characteristics, a combination of drugs is used, which is referred to as balanced anaesthesia [2]. Balanced anesthetic techniques using intravenous (IV) anesthetics produce rapid onset, redistribution and clearance along with

Copyright: The authors. This article is an open access article licensed under the terms of the Creative Commons Attributin License (http:// creative commons.org/licenses/by/2.0) which permits unrestricted use, distribution and reproduction in any medium, provided the work is properly cited. nonappearance of disadvantages of inhalant anesthetics like use of a cumbersome and costly anesthetic machines [3], exposure of operating-room personnel to the pollution [4], explains the skewed interest of veterinarians towards the use of total intravenous anaesthesia (TIVA) [5].

Propofol infusion as $1 \%$ emulsion may be used as part of TIVA regime and has established itself as a qualified maintenance anesthetic with a good quality recovery [6]. Propofol as sole agent for TIVA is generally unsatisfactory, since its poor analgesic property. Consequently, it is necessary to supplement propofol with an analgesic and muscle relaxant [7].

Xylazine and dexmedetomidine, being two $\alpha_{2}$-adrenergic receptor agonists, mediate sedative, anxiolytic and analgesic effects [8]. The $\alpha_{2} / \alpha_{1}$-receptor 
binding selectivity indicates that the medetomidine is more selective and specific $\alpha_{2}$-adrenergic receptor agonist than xylazine [9]. Dexmedetomidine is a potent and selective $\alpha_{2}$-adrenergic agonist, the active enantiomer of medetomidine [10] and clinical effects are presumed to be comparable with those of racemic medetomidine [11]. However, studies showing the comparative anesthetic evaluation of TIVA comprising combination of propofol premedicated with dexmedetomidine and atropine with combination of propofol premedicated with xylazine and atropine in surgical management of canine patients are lacking.

In the present study, we evaluated and compared the clinico-physiological, hemodynamic and hematobiochemical effects in response to different TIVA techniques using atropine, xylazine/dexmedetomidine, propofol in canine patients.

\section{Materials and Methods}

\section{Animals}

Twelve nondescript adult canines of either sex weighing $12-20 \mathrm{~kg}$ were used in this prospective clinical study and divided randomly into two groups $\mathrm{X}$ and $\mathrm{D}$ consisting of six animals each based on the anesthetic regimen given. The animals were apparently healthy, vaccinated and dewormed with free access to feed and water but remained off feed for $16 \mathrm{~h}$, and water was withheld for 8-12 h prior to the start of the surgery.

\section{Anesthetic protocols}

Anaesthesia was achieved by administration of atropine $(0.045 \mathrm{mg} / \mathrm{kg}$ body weight intramuscular), xylazine $(0.5 \mathrm{mg} / \mathrm{kg}$ body weight IV) and propofol (as IV till the induction and continuous IV infusion for maintenance) sequentially at $5 \mathrm{~min}$ intervals. Anesthetic protocol used in group D is similar to that of group $\mathrm{X}$ but instead of xylazine, dexmedetomidine was administered intravenously at the rate of $10 \mu \mathrm{g} / \mathrm{kg}$ body weight.

\section{Evaluation of clinico-physiological parameters}

The baseline values (time $=0$ ) for physiological and clinical parameters were made before injection of the drug. The examiner for the subjective determination of scores for various reflexes and jaw tone was not blinded, but was the same person during each trial throughout the period of study. Palpebral, corneal and pedal reflexes were recorded at 0 min and then at 5, 10, 15, 30, 45, 60, 75, 90, 105 and 120 min after injection of drugs or till the end of the surgical procedure and graded in a scale of 1-4, where 1 represents no change in reflex, 2 represents moderate reflex, 3 represents sluggish reflex and 4 represents absence of reflex. Similarly, tonicity of jaw muscle was recorded as above and graded in a scale of 1-4, where 1 represents normal tone, 2 represents moderate tone, 3 represents sluggish tone, and 4 represents the absence of jaw tone. Physiological parameters such as heart rate (HR- beats/min), pulse rate (PR- beats/min), respiratory rate (RR- breaths/min), rectal temperature $\left(\mathrm{RT}-{ }^{\circ} \mathrm{C}\right.$ ) and hemodynamic parameters like systolic blood pressure (SBP- $\mathrm{mm}$ of $\mathrm{Hg}$ ), diastolic blood pressure (DBP- mm of $\mathrm{Hg}$ ), mean arterial pressure (MAP- $\mathrm{mm}$ of $\mathrm{Hg}$ ) and haemoglobin oxygen saturation $\left(\mathrm{SpO}_{2}-\%\right)$ were also recorded at same time intervals. Duration of maintenance of anaesthesia (start of propofol administration till the cessation), total duration of anaesthesia (induction of anaesthesia till appearance of pedal reflex) and recovery time (of propofol administration to reappearance of pedal reflex) were calculated in minutes. Total dose of propofol for induction $(\mathrm{mg} / \mathrm{kg})$ and rate of infusion of propofol (mg/kg body weight/min) were also calculated in each group.

\section{Evaluation of hematobiochemical parameters}

Blood samples were also collected at time zero before drug administration and at 30 and 60 min after induction of anaesthesia for the estimation of total leukocyte count (TLC) $\left(\times 10^{9} / \mathrm{L}\right)$, differential leukocyte count (DC) (\%), packed cell volume (PCV) (L/L), haemoglobin $(\mathrm{g} / \mathrm{L})$, blood glucose $(\mathrm{mg} / \mathrm{dL})$, plasma urea nitrogen $(\mathrm{mg} / \mathrm{dL})$, creatinine $(\mathrm{mg} / \mathrm{dL})$ and corti$\mathrm{sol}(\mathrm{nmol} / \mathrm{L})$.

\section{Statistical analysis}

Analysis of variance and Duncan's multiple range tests were used to compare the means at different intervals among different groups. Paired - t-test was used to compare the mean values at different levels with their respective base value in each group [12]. For non-parametric observations Kruskal-Wallis oneway test was used to compare the mean between the groups at corresponding intervals [13].

\section{Results}

\section{Clinical parameters}

The body weight of animals was $14.27 \pm 3.2 \mathrm{~kg}$. The pedal reflex scores increased non-significantly (p>0.05) after administration of xylazine/dexmedetomidine and started to abolish at $10 \mathrm{~min}$, followed by complete abolishment from 15 to $75 \mathrm{~min}$ and then remained sluggish until the end (Figure-1). The

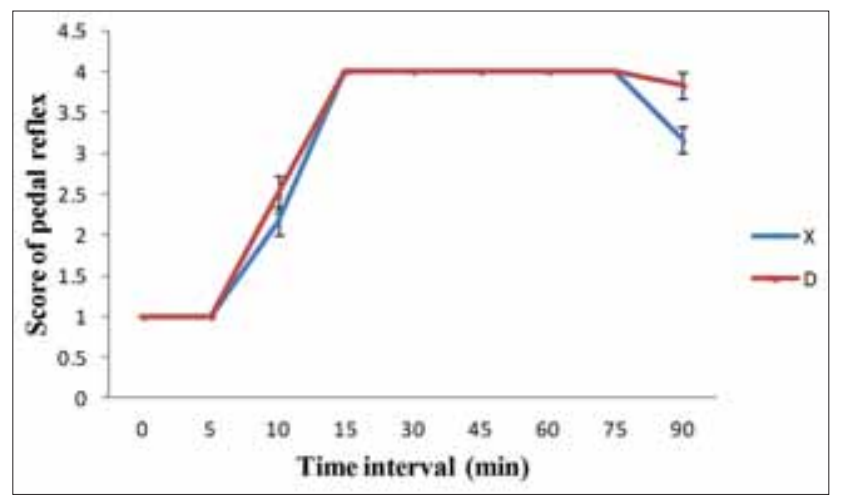

Figure-1: Mean \pm Standard error scores of pedal reflex in animals of different groups. * Significantly different from the base value $(p<0.05)$. **Significantly different from the base value $(p<0.01)$. 
palpebral reflex scores increased non-significantly ( $>0.05$ ) from $10 \mathrm{~min}$ up to $60 \mathrm{~min}$ in group $\mathrm{X}$ and 75 min in group $\mathrm{D}$, which was followed by non-significant $(\mathrm{p}>0.05)$ decrease in the palpebral reflex score (Figure-2). The corneal reflex followed the similar trend like other clinical reflexes (Figure-3). As shown in the Figure-4 jaw tone was present in the animals of group $\mathrm{X}$ and remained sluggish in group $\mathrm{D}$ after the administration of respective preanesthetics

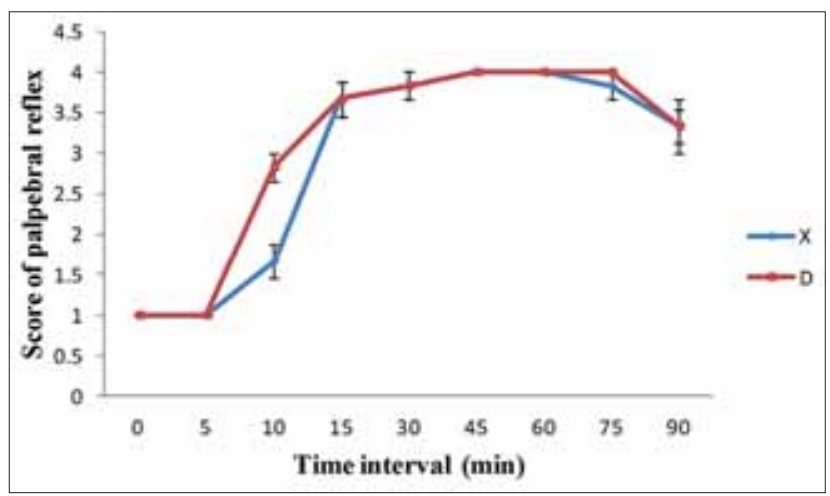

Figure-2: Mean \pm Standard error scores of palpebral reflex in animals of different groups. * Significantly different from the base value $(p<0.05)$. **Significantly different from the base value $(p<0.01)$.

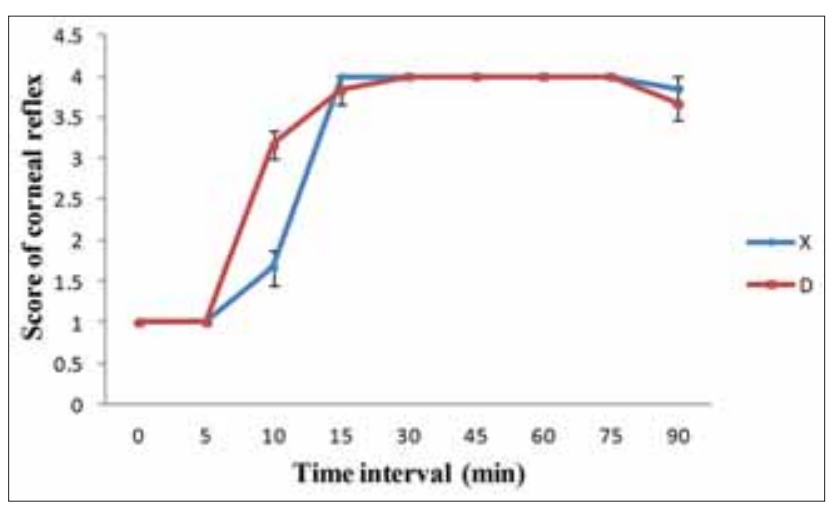

Figure-3: Mean \pm Standard error scores of corneal reflex in animals of different groups. *Significantly different from the base value $(p<0.05)$. ** Significantly different from the base value $(p<0.01)$.

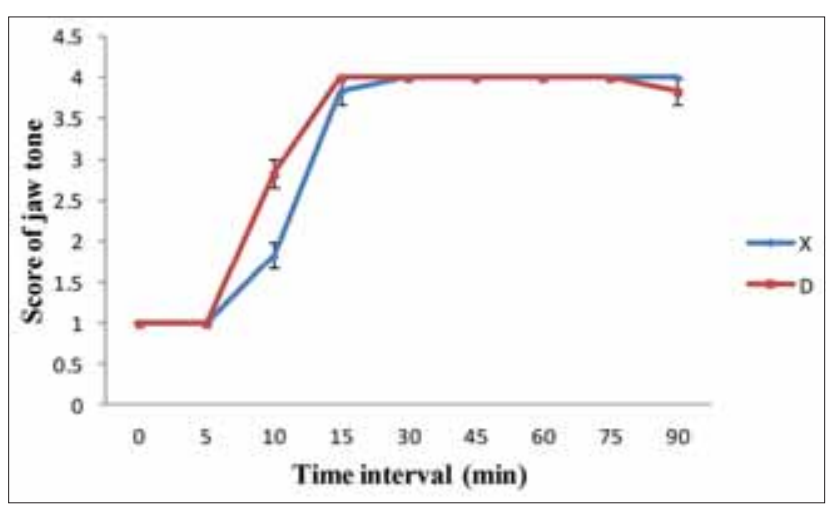

Figure-4: Mean \pm Standard error scores of jaw tone in animals of different groups. *Significantly different from the base value $(p<0.05)$. **Significantly different from the base value $(p<0.01)$. at $10 \mathrm{~min}$ followed by complete abolishment after propofol administration. Comparison among the different groups revealed that there was no significant ( $p>0.05)$ difference between groups during the evaluation of clinical reflexes and jaw tone score at various intervals.

\section{Dose rates of propofol during induction and maintenance}

The induction dose of propofol $(\mathrm{mg} / \mathrm{kg})$ in groups $X$ and $D$ was $3.17 \pm 0.21$ and $2.72 \pm 0.15 \mathrm{mg} / \mathrm{kg}$ respectively which were not significantly $(p>0.05)$ different to each other. The rate of infusion of propofol for maintenance of anaesthesia in groups $\mathrm{X}$ and $\mathrm{D}$ was $0.33 \pm 0.02$ and $0.35 \pm 0.02 \mathrm{mg} / \mathrm{kg} / \mathrm{min}$ respectively which were not significantly ( $>0.05)$ different to each other. The duration of maintenance of anaesthesia in groups $\mathrm{X}$ and $\mathrm{D}$ was $57.17 \pm 3.78$ and $35.83 \pm 1.82$ min respectively which were significantly $(p<0.01)$ different to each other. The total duration of anaesthesia in groups $\mathrm{X}$ and $\mathrm{D}$ was $72.5 \pm 3.35 \mathrm{~min}$ and $54.33 \pm 2.99$ min respectively which were significantly $(p<0.01)$ different to each other. The recovery time in group $\mathrm{X}$ and $\mathrm{D}$ was $11.17 \pm 1.14 \mathrm{~min}$ and $13.67 \pm 1.02 \mathrm{~min}$ respectively with no significant ( $>0.05$ ) difference among different groups.

\section{Physiological parameters}

As shown in Figure- 5 the HR increased non-significantly ( $>0.05$ ) in group $X$ at 5 min after atropine administration followed by a significant decrease $(\mathrm{p}<0.01)$ from $10 \mathrm{~min}$ up to $15 \mathrm{~min}$. It increased thereafter and maintained around the base line till the end of the observation period. Like group $\mathrm{X}$, the HR increased non-significantly $(\mathrm{p}>0.05)$ in group $\mathrm{D}$ at five but followed an opposite trend to group $\mathrm{X}$ subsequently. Comparison between both groups suggested a significant difference $(\mathrm{p}<0.05)$ among $\mathrm{HR}$ at $10 \mathrm{~min}$ and 15 min time intervals. In group $\mathrm{X}$ there was a non-significant $(\mathrm{p}>0.05)$ decrease in the $\mathrm{RR}$ at $5 \mathrm{~min}$. However, the decrease in RR was significant $(\mathrm{p}<0.01)$ from $10 \mathrm{~min}$ until the end of the observation period, where it remained lower than

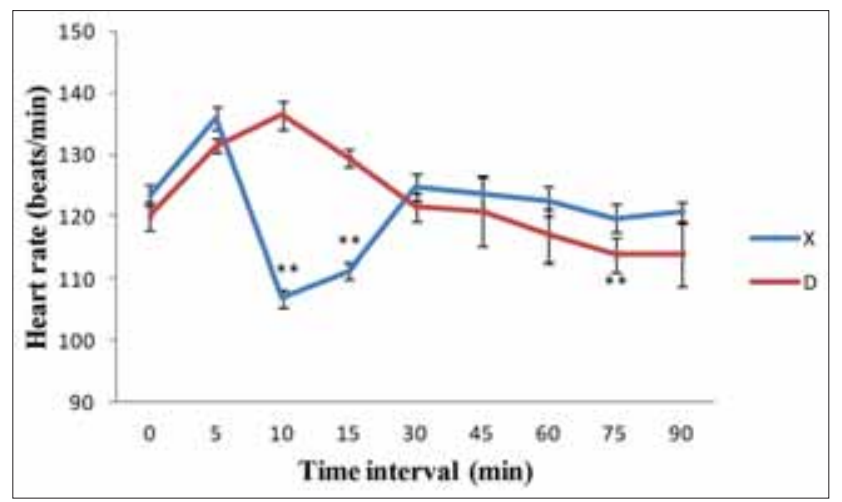

Figure-5: Mean \pm Standard error values of heart rate in animals of different groups. *Significantly different from the base value $(p<0.05)$. ** Significantly different from the base value $(p<0.01)$. 
the base value as shown in Figure-6. In group D, RR decreased non-significantly ( $>>0.05)$ from 5 min but the decrease was significant $(\mathrm{p}<0.01)$ at $10 \mathrm{~min}$ and values remained significantly $(\mathrm{p}<0.01)$ lower than the base value. Comparison between both groups suggested a significant difference $(\mathrm{p}<0.05)$ among $\mathrm{RR}$ at $5 \mathrm{~min}$ and 15 min time intervals. In group $\mathrm{X}$ there was a slight and non-significant $(p>0.05)$ decrease in $\mathrm{RT}$ at $10 \mathrm{~min}$, which decreased significantly $(\mathrm{p}<0.05)$ at $15 \mathrm{~min}$ and it remained significantly $(\mathrm{p}<0.01)$ less from 30 min until the end of observation period shown in Figure-7. In group D, there was a slight and non-significant ( $>0.05$ ) increase in RT at $5 \mathrm{~min}$, 10 min, which is followed by a significant $(\mathrm{p}<0.01)$ decline in RT from 15 min onwards. Comparison between both groups suggests that there was no significant difference in the RT values among different groups.

\section{Hemodynamic parameters}

As shown in Figure-8 in group $\mathrm{X}$ there was a significant $(\mathrm{p}<0.05)$ decrease in SBP at $5 \mathrm{~min}$ followed by a non-significant ( $p>0.05)$ increase in SBP from 10 to $15 \mathrm{~min}$ time interval. After this there was a significant $(\mathrm{p}<0.05)$ decline in SBP at $30 \mathrm{~min}$ and 60 min time intervals and highly significant $(\mathrm{p}<0.01)$

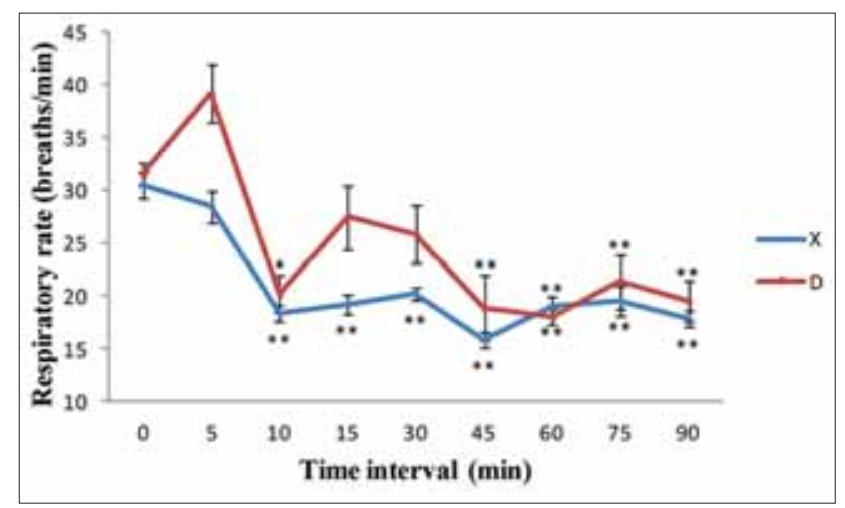

Figure-6: Mean \pm Standard error values of respiratory rate in animals of different groups. *Significantly different from the base value $(p<0.05)$.**Significantly different from the base value $(p<0.01)$.

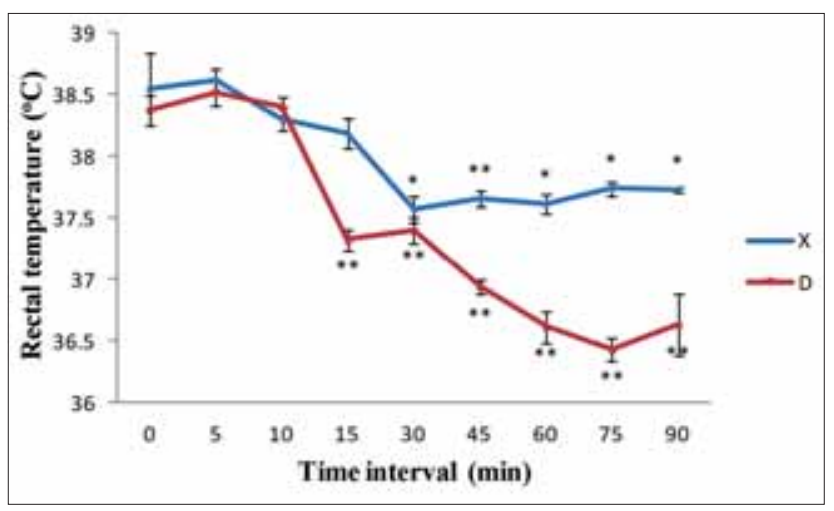

Figure-7: Mean \pm Standard error values of rectal temperature in animals of different groups. *Significantly different from the base value $(p<0.05)$. **Significantly different from the base value $(p<0.01)$. decline in SBP at $45 \mathrm{~min}, 75 \mathrm{~min}$ and $90 \mathrm{~min}$ time intervals. In group D there was a non-significant (p>0.05) decrease in SBP at 5 min followed by a non-significant ( $>0.05)$ increase in SBP at $10 \mathrm{~min}$ time interval. After this, there was a non-significant ( $>0.05$ ) decline in SBP from 30 to 75 min time interval followed by a non-significant $(\mathrm{p}>0.05)$ rise in SBP at 90 min time interval. Comparison between both groups suggested that there was a significant difference $(p<0.05)$ among SBP at $30 \mathrm{~min}, 45 \mathrm{~min}$ and 90 min time intervals. As shown in Figures- 9 and 10 , values of DBP and MAP showed almost similar trends with respect to values of SBP of corresponding groups and comparison between both groups suggests that there was a significant difference $(p<0.05)$ in the DBP and MAP values among different groups. As shown in Figure-11 in group $\mathrm{X}$ the $\mathrm{SpO}_{2}$ remained almost similar or slightly increased non-significantly $(\mathrm{p}>0.05)$ at different intervals but significantly $(\mathrm{p}<0.01)$ decreased at $5 \mathrm{~min}$ and 10 min time interval when compared to the base value. In group $\mathrm{D}$ the $\mathrm{SpO}_{2}$ remained almost similar or slightly increased non-significantly $(p>0.05)$ at different intervals, but significantly $(\mathrm{p}<0.01)$ decreased at 5 min time interval as compared to the base value. Comparison between both groups

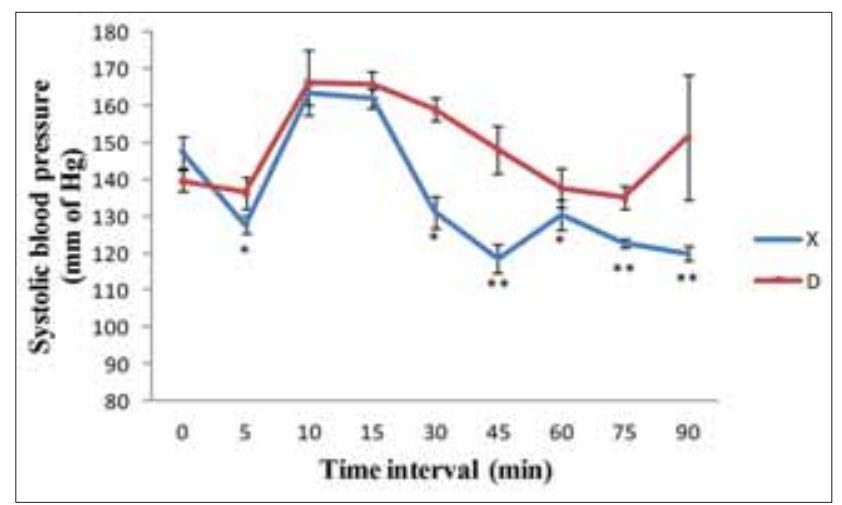

Figure-8: Mean \pm Standard error values of systolic blood pressure in animals of different groups. *Significantly different from the base value $(p<0.05)$. ** Significantly different from the base value $(p<0.01)$.

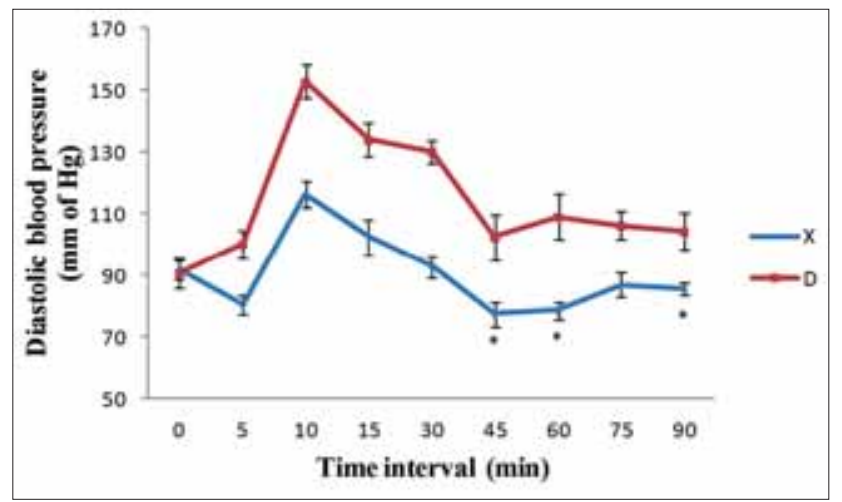

Figure-9: Mean \pm Standard error of diastolic blood pressure in animals of different groups. * Significantly different from the base value $(p<0.05)$. **Significantly different from the base value $(p<0.01)$. 


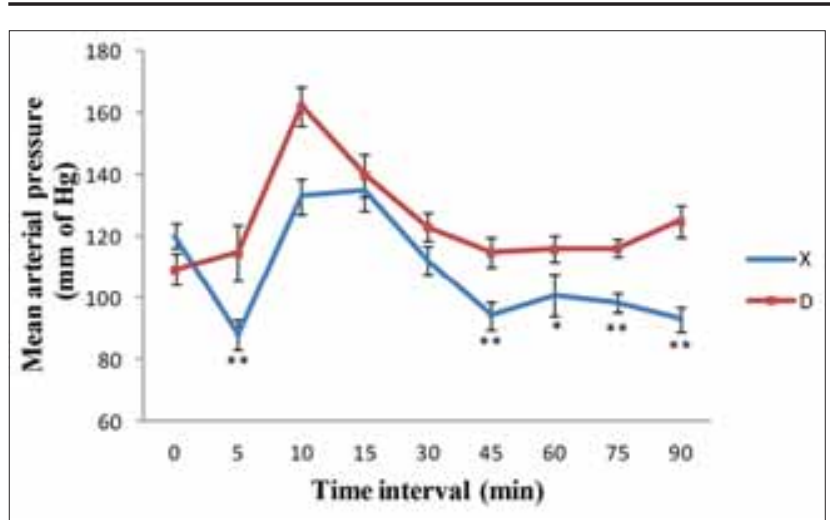

Figure-10: Mean \pm Standard error values of mean arterial pressure in animals of different groups. *Significantly different from the base value $(p<0.05)$. **Significantly different from the base value $(p<0.01)$.

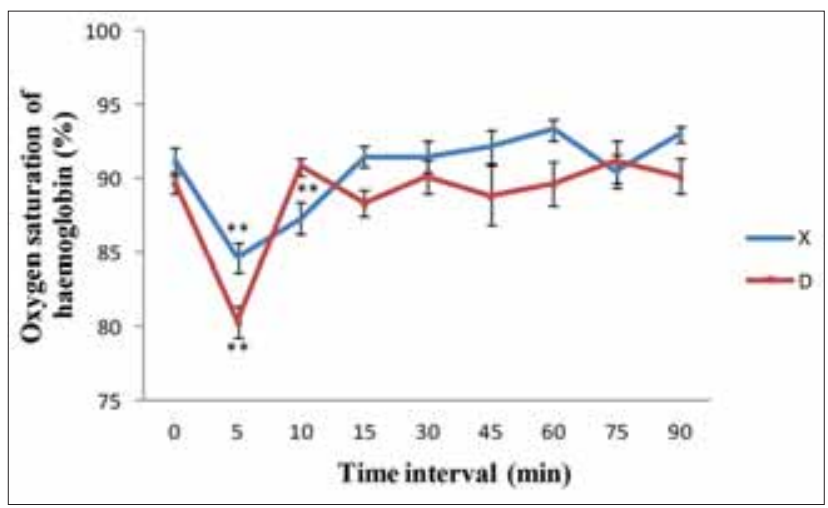

Figure-11: Mean \pm Standard error values of oxygen saturation of haemoglobin in animals of different groups. $*$ Significantly different from the base value $(p<0.05)$. $* *$ Significantly different from the base value $(p<0.01)$.

suggests that there was no significant difference in the $\mathrm{SpO}_{2}$ values among different groups.

\section{Hematological parameters}

Values of Hb and PCV showed a non-significant increase at $30 \mathrm{~min}$ in group $\mathrm{X}$ followed by a non-significant ( $>0.05$ ) decrease at $60 \mathrm{~min}$, but remained below the base value as shown in Table-1. A significant $(p<0.05)$ decrease in $\mathrm{Hb}$ and non-significant $(\mathrm{p}>0.05)$ decrease in PCV from the base value were recorded in group $\mathrm{D}$ at $30 \mathrm{~min}$, followed by a non-significant $(\mathrm{p}>0.05)$ rise at $60 \mathrm{~min}$. In group X, TLC showed a non-significant $(p>0.05)$ decrease at $30 \mathrm{~min}$, followed by a significant $(\mathrm{p}<0.05)$ decrease at $60 \mathrm{~min}$ and in group D, TLC showed a non-significant $(\mathrm{p}>0.05)$ increase at $30 \mathrm{~min}$ followed by non-significant $(\mathrm{p}>0.05)$ decrease at $60 \mathrm{~min}$. Neutrophil count showed non-significant $(p>0.05)$ increase in both the groups whereas lymphocyte count showed a significant $(\mathrm{p}<0.05)$ decrease in group $X$ and non-significant $(p>0.05)$ decrease in group D. Eosinophil count showed a non-significant $(p>0.05)$ increase in group $X$ whereas it showed a non-significant $(\mathrm{p}>0.05)$ decrease in group $\mathrm{D}$. Comparison among different groups revealed no significant $(p>0.05)$ difference in the hematological values between the groups as shown in Table- 1 .

\section{Biochemical parameters}

Values of glucose showed a non-significant $(p>0.05)$ increase in group $X$ whereas its value showed non- a significant decline in group $\mathrm{D}$ that remained below the base value. Comparison among different groups revealed that at 60 min the value of glucose in group $X$ was significantly $(\mathrm{p}<0.05)$ higher than in group D. Values of urea nitrogen and creatinine showed a similar pattern in both the groups where there was a non-significant $(\mathrm{p}>0.05)$ decrease at $30 \mathrm{~min}$ followed by a non-significant ( $>0.05)$ increase at $60 \mathrm{~min}$. But the comparison among different groups revealed that at 60 min the value of creatinine in group $X$ was significantly $(\mathrm{p}<0.05)$ higher than in group $\mathrm{D}$. Values of cortisol showed non-significant ( $>>0.05)$ increase in both the groups but group $\mathrm{X}$ showed a significantly $(p<0.05)$ lower value of plasma cortisol than group $D$ at $30 \mathrm{~min}$.

\section{Discussion}

\section{Clinical parameters}

Clinical observations like pedal, palpebral and corneal reflexes were satisfactory indicators for ascertaining the onset and depth of analgesia and anaesthesia. Scores of all the reflexes increased after the administration of xylazine/dexmedetomidine and propofol in both the groups. Xylazine group caused a moderate decrease in all the reflexes whereas dexmedetomidine group scored higher with moderate loss of all the reflexes due to high potency owing to the specificity of medetomidine for $\alpha_{2}$-adrenoreceptors than xylazine [9]. All the reflexes were abolished completely after induction of anaesthesia with propofol in the both the groups suggesting that the surgical stage of anaesthesia has reached [14]. The cumulative effect of xylazine/dexmedetomidine and general anesthetic propofol might have caused attenuation of all the reflexes. Resistance to open the mouth fully is lost in moderate anaesthesia, hence jaw tone is considered to be a useful indicator of anaesthesia $[15,16]$. Jaw tone became sluggish after the administration of xylazine/dexmedetomidine in both the groups due to inhibition of $\alpha_{2}$ adrenoceptors in the interneuron level of spinal cord [17]. But the jaw tone score was more in the dexmedetomidine group than the xylazine group due to the higher potency of dexmedetomidine [9].

\section{Dose rates of propofol during induction and maintenance \\ $\alpha_{2}$-adrenergic agonists have marked anes- thetic sparing effects both for the induction and maintenance of anaesthesia. Premedication with dexmedetomidine and xylazine was found to decrease anesthetic requirements during anaes- thesia with propofol $[14,18]$. Induction doses of propofol in the groups $X$ and $D$ were $3.17 \pm 0.21$ and $2.72 \pm 0.15 \mathrm{mg} / \mathrm{kg}$ respectively in accordance with the reported induction dose of 2.2-3.3 mg/kg [18].}


Table-1: Effects of intravenous administration of xylazine/dexmedetomidine along with propofol on haematological and biochemical parameters in canine patients (mean $\pm \mathrm{SE}$ ).

\begin{tabular}{|c|c|c|c|c|}
\hline Parameters & Group\# & Baseline & $30 \mathrm{~min}$ & $60 \mathrm{~min}$ \\
\hline \multirow[t]{2}{*}{$\mathrm{Hb}(\mathrm{g} / \mathrm{L})$} & $x$ & $10.62 \pm 0.31$ & $11.00 \pm 0.42$ & $9.90 \pm 0.38$ \\
\hline & $\mathrm{D}$ & $12.38 \pm 0.42$ & $10.67 \pm 038 *$ & $12.15 \pm 0.42$ \\
\hline \multirow[t]{2}{*}{ PCV (L/L) } & $x$ & $0.39 \pm 0.01$ & $0.41 \pm 0.02$ & $0.39 \pm 0.02$ \\
\hline & D & $0.39 \pm 0.01$ & $0.35 \pm 0.02$ & $0.38 \pm 0.03$ \\
\hline \multirow[t]{2}{*}{ Neutrophil count (\%) } & $x$ & $64.17 \pm 3.66$ & $68.67 \pm 4.00$ & $69.33 \pm 3.27$ \\
\hline & $\mathrm{D}$ & $69.83 \pm 3.24$ & $68.17 \pm 2.63$ & $70.17 \pm 2.85$ \\
\hline \multirow[t]{2}{*}{ Lymphocyte count (\%) } & $x$ & $31.17 \pm 2.12$ & $23.33 \pm 2.20 *$ & $27.67 \pm 3.56$ \\
\hline & $\mathrm{D}$ & $30.17 \pm 0.79$ & $28.50 \pm 1.06$ & $23.33 \pm 2.44 *$ \\
\hline \multirow[t]{2}{*}{ Eosinophil count (\%) } & $x$ & $3.67 \pm 0.92$ & $4.50 \pm 1.02$ & $5.33 \pm 1.05$ \\
\hline & $\mathrm{D}$ & $5.00 \pm 1.71$ & $5.33 \pm 1.26$ & $4.67 \pm 1.20$ \\
\hline \multirow[t]{2}{*}{ TLC (\%) } & $x$ & $9.33 \pm 0.76$ & $7.67 \pm 0.67$ & $6.33 \pm 0.61 *$ \\
\hline & $\mathrm{D}$ & $12.07 \pm 1.70$ & $12.77 \pm 1.48$ & $8.68 \pm 0.78$ \\
\hline \multirow[t]{2}{*}{ Glucose (mg/dL) } & $x$ & $73.16 \pm 3.57$ & $79.33 \pm 3.49$ & $82.66 \pm 4.84$ \\
\hline & $\mathrm{D}$ & $76.66 \pm 6.31$ & $86.83 \pm 5.48$ & $68.83 \pm 2.45$ \\
\hline \multirow[t]{2}{*}{ Plasma urea nitrogen $(\mathrm{mg} / \mathrm{dL})$} & $x$ & $14.66 \pm 1.40$ & $11 \pm 1.84^{*}$ & $15 \pm 1.87$ \\
\hline & $\mathrm{D}$ & $13.33 \pm 2.06$ & $13 \pm 2.50$ & $17.66 \pm 0.88$ \\
\hline \multirow[t]{2}{*}{ Creatinine $(\mathrm{mg} / \mathrm{dL})$} & $x$ & $1.78 \pm 0.35$ & $1.033 \pm 0.28$ & $1.75 \pm 0.27$ \\
\hline & $\mathrm{D}$ & $1.71 \pm 0.36$ & $1.07 \pm 0.27$ & $2.01 \pm 0.22$ \\
\hline \multirow[t]{2}{*}{ Cortisol (nmol/L) } & $x$ & $46.76 \pm 3.83$ & $73.43 \pm 4.45$ & $98.56 \pm 8.29$ \\
\hline & $\mathrm{D}$ & $71 \pm 5.81$ & $110 \pm 6.59$ & $110.33 \pm 9.58$ \\
\hline
\end{tabular}

\#X=Xylazine and propofol administered group, $\mathrm{D}=$ dexmedetomidine and propofol administered group. *Significantly different from the base value $(p<0.05), * *$ Significantly different from the base value $(p<0.01)$. Hb=Haemoglobin, $\mathrm{PCV}=$ Packed cell volume, $\mathrm{TLC}=$ Total leucocyte count, IV=Intravenous

However, dexmedetomidine group had relatively less dose of propofol for induction than xylazine group as former was more potent than latter at equal doses. Rate of infusion of propofol for maintenance of anaesthesia in group $X$ was $0.33 \pm 0.02 \mathrm{mg} / \mathrm{kg} / \mathrm{min}$ and was $0.35 \pm 0.02 \mathrm{mg} / \mathrm{kg} / \mathrm{min}$ in group $\mathrm{D}$ which was in accordance earlier studies where rate of infusion of propofol by CII was in the range of $0.15-0.5 \mathrm{mg} / \mathrm{kg} / \mathrm{min}$ in dogs $[15,19]$. The propofol requirement for induction and maintenance of anaesthesia was found to be greatly reduced by premedication with $\alpha_{2}$ agonists [14]. The duration of maintenance of anaesthesia for group $X$ was $57.17 \pm 3.78 \mathrm{~min}$ and in group $\mathrm{D}$, it was $35.83 \pm 1.82$ min which was in the range of 38-62 min duration of maintenance of anaesthesia in canines [14]. Although total duration of anaesthesia dependent on the nature of surgical procedure, in groups $\mathrm{X}$ and $\mathrm{D}$, it was $72.5 \pm 3.35$ and $54.33 \pm 2.99 \mathrm{~min}$ respectively. The duration was the shorter in $\mathrm{D}$ as compared to group $\mathrm{X}$ and falling in the range of 66-79 min which has been reported by Surbhi (2010) [14]. Recovery from anaesthesia in all the groups was smooth and uneventful and its duration was higher in dexmedetomidine group which in accordance to an earlier study in humans where a low dose of dexmedetomidine was found to reduce the propofol infusion dose but did not affect the pharmacokinetics of propofol or recovery time after infusion [20]. Rapid and smooth recovery recorded in the present study was in accordance with that reported in the earlier studies [21] in dogs. It is evident from the present study that propofol is an ideal general anesthetic for longer duration of surgeries requiring an hour or more, without significantly affecting the vital body functions.

\section{Physiological and hemodynamic parameters}

HR increased after the administration of atropine in all the groups which might be due to the antagonistic activity of atropine with acetylcholine [22]. $\alpha_{2}$ agonists affected cardiovascular function [23] with increased vagal tone and decreased sympathetic activity to effect bradycardia [24]. However, in the present study, an increase in HR was observed after the administration of xylazine/ dexmedetomidine which is in accordance with the earlier studies in which preemptive administration of atropine was capable of reversing $\alpha_{2}$ agonist-induced bradyarrhythmias in dogs [25]. After the administration of propofol, HR increased similar to earlier findings reported in dogs $[21,26]$. This may be due to positive chronotropic effect of propofol [14] or, increased myocardial blood flow [27] or, combination of both. RR was not much affected by the administration of atropine. However, depression in RR was observed after the administration of preanesthetics due to direct depression of the respiratory centers in the brain [28]. Induction of anaesthesia with propofol also caused a decrease in RR that was in accordance to earlier studies in dogs [21]. Respiratory depression and apnea, being the most commonly reported adverse effect of propofol anaesthesia, was proportional to rate of infusion of propofol $[29,30]$. In the present study, the rate of infusion of propofol was the most vital parameter to be controlled based on the RR and $\mathrm{SpO}_{2}$. RT decreased in all the groups after the administration of preanesthetics that was due to CNS depression in combination with a reduction in muscular activity and basal metabolic rate [31]. The induction of anaesthesia with propofol caused a further significant decrease in the RT but remained within an 
acceptable range, which was in accordance to earlier studies [21,26,30]. Blood pressure (BP) increased after the administration of atropine, and there was further significant increase in BP after the administration of xylazine or dexmedetomidine, which was due to the stimulation of peripheral $\alpha_{2 \mathrm{~B}}$ agonist receptors mediated transient initial hypertension of variable duration [32]. The transient hypertension induces a reflex baroreceptor mediated physiologic bradycardia [33]. In the present study, the initial hypertension and subsequent decrease in BP might have occurred by a similar mechanism. Propofol has been reported to decrease systemic arterial BP due to peripheral vasodilation [34], direct negative inotropic action and direct decrease of arterial and venous vascular tone [14]. The findings of the present study suggest that administration of propofol helps to alleviate dexmedetomidine induced vasoconstriction, which is in accordance with the previous study [35]. Initial decrease in $\mathrm{SpO}_{2}$ in animals of all the groups may be attributed to vasoconstriction [36] caused by xylazine/dexmedetomidine as reported by Kuusela et al. (2000) [37]. $\mathrm{SpO}_{2}$ decreased after the induction of anaesthesia with propofol in all the groups due to the respiratory depression causing a decrease in RR, which was in accordance to earlier studies $[29,30,38]$.

\section{Hematological parameters}

Decrease in Hb and PCV values was attributed to pooling of circulating erythrocytes in the spleen or other reservoirs secondary to decreased sympathetic stimulation $[14,28]$ or due to intercompartmental fluid shift in order to maintain normal cardiac output [39] or due to hemodilution in response to fluid therapy $[14,28]$. The present finding is in accordance with the earlier studies in which a significant decrease in $\mathrm{Hb}$ and PCV was observed after the administration of $\alpha_{2}$ agonists in dogs. A similar decrease in the $\mathrm{Hb}$ level was also recorded in the propofol anaesthesia [40]. However, an increase in PCV was also reported in studies involving $\alpha_{2}$ agonists in goats, and this was explained by increased urine production due to activation of capillary fluid shift mechanism or by the release of the splenic red blood cells reservoir [28]. Differential leukocyte count showed a rise in neutrophil count and the lymphocyte count in each group varied conversely to the neutrophil count. There was no regular pattern of change in the eosinophil count. No significant change in monocyte and basophil count was noticed in any group at any interval. Increase in neutrophil count may be due to severe stress inflicted upon the animal during painful surgeries along with the anesthetic stress leading to stimulation of the adrenal cortex and subsequent production of glucocorticoid that acts on the circulating neutrophils [41]. A similar mechanism might have involved in increasing the neutrophil count during the present study which was in accordance to an earlier study in dogs [42]. The decrease in TLC, observed in the present study, was consistent with the findings of earlier studies using propofol in dogs [40] and using $\alpha_{2}$ agonists in dogs $[14,28]$ which might be due to the pooling of circulating blood cells in spleen or other reservoirs secondary to decreased sympathetic activity in dogs [41]. An increase in TLC has also been reported in dogs [42] which explain the rise in TLC in group $\mathrm{D}$.

\section{Biochemical parameters}

Hyperglycemic effects of $\alpha_{2}$ agonists medetomidine [14] and dexmedetomidine [23] have been investigated in earlier studies which is due to suppression of insulin release, stimulation of glucagon release, or both, in $\alpha$ and $\beta$ cells of the pancreas, respectively [43]; also recorded with propofol anaesthesia in dogs [40]. Hyperglycemia observed in the present study may be due to the said mechanisms. The high rise of glucose during anaesthesia in the present study might also be attributed to decreased membrane transport of glucose, decreased glucose utilization, impaired insulin activity and increased blood concentration of adrenocortical hormones as reported in dogs [44]. Increase in BUN after the administration of propofol has been recorded [45] which may be due to reduced blood flow to kidneys leading to retention of nitrogenous substances in the blood. This explains the increase in plasma urea nitrogen values in the present study. However, in the present study, the decrease in PUN might be due to the continuous infusion of IV fluids thus maintaining the normal kidney functions. However, all the observed values of PUN were within the normal physiological limits. The fluctuations in creatinine values were attributed to the inhibitory effect of drugs on the renal blood flow, increased creatinine production from muscle damage and amino acid degradation $[28,44]$. However, in the present study, the creatinine level was within the normal physiological limits and the decrease may be due to continuous IV fluid infusion. Cortisol value indicates stress level of the animal. Various studies have shown that $\alpha_{2}$ agonists reduce the preoperative levels of stress-related hormones and thus attenuate the stress response of surgery in dogs [46]. Clinical doses of IM racemic medetomidine had no influence on canine cortisol levels [47]. Even propofol infusion anaesthesia had no influence on plasma cortisol concentration at the end of anaesthesia and during recovery in dexmedetomidine-premedicated dogs [48]. In the present study, cortisol values might have increased before anaesthesia as the animal was already under stress before surgery owing to the pain and unnatural environment in the clinics. Then owing to the stress attenuation response of xylazine/dexmedetomidine, the cortisol levels might have reduced at 30 min interval. However, the cortisol levels ultimately increased due to the severe anesthetic and surgical stress in the animals. The overall observation on blood biochemical 
parameters indicated that the anesthetic and surgical stress was responsible for the changes in their values, but the changes were transient in nature and not of any clinical significance.

\section{Miscellaneous clinical observations}

Among other observations Diuresis was observed in the animals of both xylazine and dexmedetomidine groups attributed to $\alpha_{2}$ agonists mediated inhibition of release of antidiuretic hormone in dogs [49] or osmotic diuretic effect of increased blood glucose by $\alpha$, agonists [50]. Muscle twitching following the administration of medetomidine has been described in dogs [51,52] which is also observed in the present study may be a hypersensitivity response to noise [51]. Nausea was observed in one animal of dexmedetomidine group and two animals of xylaizne group during anaesthesia. Since vomiting caused by $\alpha_{2}$ adrenoceptor agonist, xylazine, in cats was shown to follow the stimulation of receptors in the chemoreceptor trigger zone in the brain [53] dexmedetomidine could have a similar effect [23]. The same mechanism might have contributed to nausea in the present study.

\section{Conclusion}

The propofol requirement for induction and maintenance of anaesthesia was found to be greatly reduced by premedication with $\alpha_{2}$ agonists. The duration of maintenance of anaesthesia was the shorter in group $\mathrm{D}$ when compared to group $\mathrm{X}$. Recovery time slightly higher in the dexmedetomidine group than the xylazine group. Although dexmedetomidine showed quicker attenuation of all clinical reflexes when compared to xylazine but auxiliary experiments would be needed to uphold the hypothesis that dexmedetomidine also possessed a local analgesic action similar to that of xylazine. HR increased due to the combined action of preemptive vagolytic atropine and propofol administration. Administration of xylazine or dexmedetomidine caused a decrease in RR and RT that was exacerbated after subsequent propofol administration, but remained within normal physiological limits. The hematological and biochemical changes recorded by these drugs were evanescent in nature and returned to basal values as the effects of these drugs weaned off. Both xylazine and dexmedetomidine caused nausea and renal diuresis. Although there was no response to external stimuli, but most had involuntary ear twitches. On the basis of findings in the present study, dexmedetomidine provided slightly better degree of basal anaesthesia than xylazine in canine patients. Atropine-xylazine-propofol and atropine-dexmedetomidine-propofol can be employed safely for anesthetic management of canine patients without significantly affecting the vital body functions. However, latter may be preferred owing to lesser doses of propofol required for induction and maintenance of anaesthesia along with a lesser degree of respiratory depression.

\section{Authors' Contributions}

BJ, JD, IN and KKS have conceived, planned and designed the study. BJ, AS, SSB have conducted the research, analyzed and kept a due record of the data. Manuscript was framed and drafted by BJ and AP under the aegis of JD. All authors read and approved the final manuscript.

\section{Acknowledgments}

The authors are thankful to the Dean, College of Veterinary Science and Animal Husbandry, Bhubaneswar and Doctor in Charge, Veterinary Hospital, Saheed Nagar, Bhubaneswar, Odisha for their support and cooperation in carrying out the study. The fund for the study was provided by Department of Veterinary Surgery and Radiology, College of Veterinary Science and Animal Husbandry, Orissa University of Agriculture and Technology, Bhubaneswar, Odisha.

\section{Competing I nterests}

The authors declare that they have no competing interests.

\section{References}

1. Vedpathak, H.S., Tank, P.H., Karle, A.S., Mahida, H.K., Joshi, D.O. and Dhami, M.A. (2009) Pain management in veterinary patients. Vet. World., 2(9): 360-363.

2. Thurmon, J.C. and Short, C.E. (2007) History and overview of veterinary anaesthesia. In: Tranquilli, W.J., Thurmon, J.C. and Grimm, K.A., editors. Lumb \& Jones' Veterinary Anaesthesia and Analgesia. $4^{\text {th }}$ ed. Blackwell Publishing Ltd., Oxford. p3-6.

3. Matthews, N.S. (2007) Inhalant anaesthetics. In: Seymour, C. and Duke Novakovski T., editors. BSAVA Manual of Canine and Feline Anaesthesia and Analgesia. $2^{\text {nd }}$ ed. British Small Animal Veterinary Association, Gloucester. p150-155.

4. Hasei, M., Hirata, T., Nishihara, H., Tanigami, H., Takashina, M. and Mori, T. (2003) Occupational exposure of operating room staff to anesthetic gases during inhaled induction - A comparison with intravenous anaesthesia induction. Masui., 52(4): 394-398.

5. Waelbers, T., Vermoere, P. and Polis, I. (2009) Total intravenous anaesthesia in dogs. Vlaams. Diergeneeskd. Tijdschr., 78(3): 160-169.

6. De Vries, A., Taylor, P.M., Troughton, G., Liu, B., Fowden, A.L. and Sear, J.W. (2013) Real time monitoring of propofol blood concentration in ponies anaesthetized with propofol and ketamine. J. Vet. Pharmacol. Ther., 36(3): 258-266.

7. Kürüm, B., Pekcan, Z., Kalender, H., Kumandaş, A., Can Mutan, O. and Elma, E. (2013) Comparison of propofol-remifentanil and propofol-fentanyl anaesthesia during ovariohysterectomy in dogs. Kafkas. Üniv. Vet. Fak. Derg., 19: A33-A40.

8. Pertovaara, A. (2013) The noradrenergic pain regulation system: A potential target for pain therapy. Eur. J. Pharmacol., 716(1-3): 2-7.

9. Scheinin, H., Virtanen, A., MacDonald, E., Lammintausta, A. and Schenin, M. (1989) Medetomidine - A novel $\alpha_{2}$-adrenoceptor agonist: A review of its pharmacodynamic effects. Prog. Neuropsychopharmacol. Biol. Psychiatry., 13: 635-651.

10. Panzer, O., Moitra, V. and Sladen, R.N. (2011) Pharmacology of sedative-analgesic agents: dexmedetomidine, remifentanil, 
ketamine, volatile anesthetics, and the role of peripheral mu antagonists. Anesthesiol. Clin., 29(4): 587-605.

11. Grimm, K.A., Tranquilli, W.J., Thurmon, J.C. and Benson, G.J. (2000) Duration of nonresponse to noxious stimulation after intramuscular administration of butorphanol, medetomidine, or a butorphanol-medetomidine combination during isoflurane administration in dogs. Am. J. Vet. Res., 61(1): 42-47.

12. Snedecor, G.W. and Cochran, W.G. (1994) Statistical Methods. $8^{\text {th }}$ ed. Iowa State University Press, Ames, IA.

13. Siegel, S. Jr. and Castellan, N.J. (1988) Norparametric Statistics for the Behavioural Sciences. $2^{\text {nd }}$ ed. McGraw Hill Book Company, New York.

14. Surbhi, Kinjavdekar, P., Amarpal, Aithal, H.P., Pawde, A.M., Pathak, M.C., Borena, B.M. and Malik, V. (2010) Physiological and biochemical effects of medetomidine- butorphanol, propofol anaesthesia in dogs undergoing orthopaedic surgery. Indian. J. Vet. Surg., 31(2): 101-104.

15. Tranquilli, W.J., Thurmon, J.C. and Grimm, K.A. (2007) Injectable and alternative anaesthetic techniques. In: Lumb, W.V. and Jones, E.W., editors. Veterinary Anaesthesia. $4^{\text {th }}$ ed. Blackwell Publishing, Ames, IA. 273-300

16. Hopster, K., Müller, C., Hopster-Iversen, C., Stahl, J., Rohn, K. and Kästner, S. (2014) Effects of dexmedetomidine and xylazine on cardiovascular function during total intravenous anaesthesia with midazolam and ketamine and recovery quality and duration in horses. Vet. Anaesth. Analg., 41(1): 25-35.

17. Sinclair, M.D. (2003) A review of the physiological effects of $\alpha$-agonists related to the clinical use of medetomidine in small animal practice. Can. Vet. J., 44(11): 885-897.

18. Dewangan, R., Tiwari, S.K., Sharda, R. and Nath, K. (2010) Clinicophysiological and cardiopulmonary response to xylazine, propofol anaesthesia in dogs. Indian. J. Vet. Surg., 31(2): 127-129.

19. Yoo-Jun, H.O., Lee-Chung, H.O., Kim, W.H., Nam, T.C., and Kweon, O.K. (2002) Anaesthetic and cardiopulmonary effects of propofol as infusion and induction anaesthesia in dogs. Korean. J. Vet. Res., 42(1): 123-130.

20. Hoy, S.M. and Keating, G.M. (2011) Dexmedetomidine. Drugs., 71(11): 1481-1501.

21. Adetunji, A., Ajadi, R.A., Adewoye, C.O. and Oyemakinde, B.O. (2002) Total Intravenous anaesthesia with propofol: Repeat bolus versus continuous propofol infusion technique in xylazine-premedicated dogs. Isr. J. Vet. Med., 57(4): 139-144.

22. Innes, I.R. and Nickerson, M. (1975) Atropine, scopolamine and related antimuscarinic drugs. In: Goodman, L.S., Gilman, A. editors. Pharmacologcal Basis of Therapeutics. $5^{\text {th }}$ ed. Macmillan Publishing Co. Inc., New York. p514-532.

23. McSweeney, P.M., Martin, D.D., Ramsey, D.S., and McKusick, B.C. (2012) Clinical efficacy and safety of dexmedetomidine used as a preanesthetic prior to general anaesthesia in cats. J. Am. Vet. Med. Assoc., 240(4): 404-412.

24. Hayashi, Y. and Maze, M. (1993) Alpha nists and anaesthesia. Br. J. Anaesth., 71(1): 108-118.

25. Ko, J.C.H., Fox, S.M., Mandsager, R.E. (2001) Effects of pre-emptive atropine administration on incidence of medetomidine induced bradycardia in dogs. J. Am. Vet. Med. Assoc., 218(1): 52-58.

26. Sharma, V. and Bhargava, M.K. (2007) Clinical effects of propofol general anaesthesia in dogs. Indian. J. Vet. Surg., 28(1): 33-34.

27. Haberer, J.P., Audibert, G., Saunier, C.G., Muller, C., Laxenairem M.C. and Hartemann, D. (1993) Effects of propofol and thiopentone on regional blood flow in brain and peripheral tissues during normoxia and hypoxia in the dogs. Clin. Physiol., 13(2): 197-207.

28. Singh, G.D., Kinjavdekar, P., Amarpal, Aithal H.P., Pawde, A.M., Zama, M.M.S., Singh, J. and Tiwary, R.
(2013) Clinicophysiological and haemodynamic effects of fentanyl with xylazine, medetomidine and dexmedetomidine in isoflurane-anaesthetised water buffaloes (Bubalus bubalis). J. S. Afr. Vet. Assoc., 84(1): 1-11.

29. Suarez, M.A., Dzikiti, B.T., Stegmann, F.G. and Hartman, M. (2012) Comparison of alfaxalone and propofol administered as total intravenous anaesthesia for ovariohysterectomy in dogs. Vet. Anaesth. Analg., 39(3): 236-244.

30. Maney, J.K., Shepard, M.K., Braun, C., Cremer, J. and Hofmeister, E.H. (2013) A comparison of cardiopulmonary and anesthetic effects of an induction dose of alfaxalone or propofol in dogs. Vet. Anaesth. Analg., 40(3): 237-244.

31. Singh, V., Amarpal, Kinjavdekar, P. and Aithal, H.P. (2009) Effect of bupivacaine on epidural analgesia produced by xylazine or medetomidine in buffaloes (Bubalus bubalis). Vet. Anaesth. Analg., 36(1): 77-85.

32. Vainio, O. and Palmu, L. (1989) Cardiovascular and respiratory effects of medetomidine in dogs and influence of anticholinergics. Acta. Vet. Scand., 30(4): 401-408.

33. Schmeling, W.T., Kampine, J.P., Roerig, D.L. and Warltier, D.C. (1991) The effects of the stereoisomers of the $\alpha_{2}$-adrenergic agonist medetomidine on systemic and coronary hemodynamics in conscious dogs. Anesthesiology., 75(3): 499-511.

34. Sooryadas, S., Amma, T., Sarda, Rajankutty, K., Gopakumar, N. and Nayar, K.N.M.(2011)Electrocardiogram changes during xylazine-propofol anaesthesia in dogs: A clinical study, Indian. J. Vet. Surg., 32(2): 129-130.

35. Thurmon, J.C., Ko, J.C.H., Benson, G.J., Tranquilli, W.J. and Olson, W.A. (1994) Hemodynamic and analgesic effects of propofol infusion in medetomidine-premedicated dogs. Am. J. Vet. Res., 55(3): 363-367.

36. Leppanen, M.K., McKusick, B.C., Granholm, M.M., Westerholm, F.C., Tulama, R. and Short, C.E. (2006) Clinical efficacy and safety of dexmedetomidine and buprenorphine, butorphanol or diazepam for canine hip radiography. J. Small. Anim. Pract., 47(11): 663-669.

37. Kuusela, E., Raekallio, M., Anttila, M., Falck, I., Mölsä, S., Vainio, O. (2000) Clinical effects and pharmacokinetics of medetomidine and its enantiomers in dogs. J. Vet. Pharmacol. Ther., 23(1): 15-20.

38. Mair, A.R., Pawson, P., Courcier, E. and Flaherty, D. (2009) A comparison of the effects of two different doses of ketamine used for co-induction of anaesthesia with a target-controlled infusion of propofol in dogs. Vet. Anaesth. Analg., 36(6): 532-538.

39. Wagner, A.E., Muir W.W.III and Hitchcliff, K.W. (1991) Cardiovascular effects of xylazine and detomidine in horses. Am. J. Vet. Res., 52(5): 651-657.

40. Khan, K.M., Mehsare, S.P., Pawshe, D.B., Patil, R.B. and Rahman, S. (2006) Effect of midazolam as a preanaesthetic to propofol anaesthesia in canines on haematological and biochemical parameters. Vet. World., 5(3): 77-80.

41. Soliman, M.K., Amrousi, S.E. and Khamis, M.Y. (1965) The influence of tranquilizers and barbiturate anaesthesia on the blood picture and electrolytes of dogs. Vet. Rec., 77: 1256.

42. Sharma, A. and Bhardwaj, H.R. (2010) Comparative evaluation of propofol alone and along with xylazine or midazolam in healthy dogs. Indian. J. Vet. Surg., 31(2): 105-108.

43. Kumar, R., Kinjavdekar, P., Amarpal, Aithal, H.P., Pawde, A.M., Kumar, A., Singh, J. and Khattri, S. (2013) Haematobiochemical effects of dexmedetomidine with and without butorphanol for propofol and ketamine anaesthesia in uremic goats. Indian. J. Vet. Surg., 34(1): 19-22.

44. Restitutti, F., Raekallio, M., Vainionpää, M., Kuusela, E. and Vainio, O. (2012) Plasma glucose, insulin, free fatty acids, lactate and cortisol concentrations in dexmedetomidine-sedated dogs with or without MK-467: A peripheral $\alpha-2$ adrenoceptor antagonist. Vet. J., 193(2): 481-485.

45. Manat, D.K.L. and Kelawala, N.H. (2004) Studies on anaesthetic evaluation of propofol-thiopental sodium as 
induction and maintenance agents in dogs. Indian. J. Vet. Surg., 25: 54.

46. Ko, J.C., Mandsager, R.E., Lange, D.N. and Fox, S.M. (2000) Cardiorespiratory responses and plasma cortisol concentrations in dogs treated with medetomidine before undergoing ovariohysterectomy. J. Am. Vet. Med. Assoc., 217(4): 509-514.

47. Ambrisko, T.D. and Hikashi, Y. (2002) Neurohormonal and metabolic effects of medetomidine compared with xylazine in beagle dogs. Can. J. Vet. Res., 66(1): 42-49.

48. Kuusela, E., Vainio, O., Short, C.E., Leppaluoto, J., Huttunen, P., Strom, S., Huju, V., Valtonen, A. and Raekallio, M. (2003) A comparison of propofol infusion and propofol/isoflurane anaesthesia in dexmedetomidine premedicated dogs. J. Vet. Pharmacol. Ther., 26(3): 199-204.
49. Manners, H. (1990) Diuresis following medetomidine. Vet. Rec., 126(7): 201.

50. Duke, T., Cox, A.K. and Remedios, A.M. (1994) The analgesic effects of administering fentanyl or medetomidine in the lumbosacral epidural space of cats. Vet. Surg., 23(2): 143-148.

51. England, G.C.W. and Clarke, K.W. (1989) The effect of route of administration upon the efficacy of medetomidine. J. Assoc. Vet. Anaesth., 16:32-34.

52. Vaha-Vahe, A.T. (1989) Clinical evaluation of medetomidine, a novel sedative and analgesic drug for dogs and cats. Acta. Vet. Scand., 30(3): 267-273.

53. Colby, E.D., McCarthy, L.E. and Borison, H.L. (1981) Emetic action of xylazine on the chemoreceptor trigger zone for vomiting in cats. J. Vet. Pharmacol. Ther., 4(2): 93-96. 